Short communication

\title{
Low-temperature preparation and characterization of iron-ion doped titania thin films
}

\author{
Chung-Hsin Lu*, Chi-Yuan Hu, Chung-Hsien Wu \\ Department of Chemical Engineering, National Taiwan University, Taipei, Taiwan, ROC
}

\section{A R T I C L E I N F O}

\section{Article history:}

Received 28 September 2007

Received in revised form 12 February 2008

Accepted 16 February 2008

Available online 23 February 2008

\section{Keywords:}

Titania

Iron

Photocatalytic

Thin films

High pressure

\begin{abstract}
A B S T R A C T
Iron-ion doped titania thin films with an anatase phase were successfully synthesized in this study using the high-pressure crystallization (HPC) process. The crystallization temperature of $\mathrm{Fe}^{3+}$-doped $\mathrm{TiO}_{2}$ thin films was markedly reduced to be as low as $125^{\circ} \mathrm{C}$. The films prepared via the HPC process have a more uniform microstructure and smaller grain sizes than the films prepared via the atmospheric-pressure annealing process. The films prepared via both processes were found to have photocatalytic properties under visible light. The films prepared via the HPC process exhibited enhanced photocatalytic activities in comparison with the films annealed via the conventional process. Increasing the annealing temperature in the HPC process resulted in an improvement in the photocatalytic properties because of an increase in the crystallinity of the prepared films. The HPC process was demonstrated to be a potential method for synthesizing visible-light driven titania thin films with enhanced photocatalytic activities at low temperatures.
\end{abstract}

(C) 2008 Elsevier B.V. All rights reserved.

\section{Introduction}

Titanium dioxide has been intensively investigated as an important material for degrading various chemical compounds under UV light irradiation because of its strong photocatalytic activity [1-5]. The powder-type photocatalysts have some disadvantages in industrial applications such as stirring problems during the reaction processes and the requirement for separation after the operation processes. Therefore, film-type photocatalysts were widely developed in order to extend the applicability of $\mathrm{TiO}_{2}$. Different methods such as the sol-gel process, chemical vapor deposition (CVD) and sputtering were employed to synthesize $\mathrm{TiO}_{2}$ thin films [6-8]. Among these processes, the sol-gel method is the most commonly used method because of its simple process and low cost materials.

$\mathrm{TiO}_{2}$ only absorbs ultraviolet (UV) light because of its large band gap $(\sim 3.2 \mathrm{eV})[9,10]$. Various transition metal ions have been used to dope into $\mathrm{TiO}_{2}$ for shifting the absorption edge to visible light region [11-14]. $\mathrm{TiO}_{2}$ thin films doped with transition metal ions have received much attention in the past few years [15-20]. Doping Fe ions has been proven to be an effective approach in enhancing the photocatalytic activity of $\mathrm{TiO}_{2}$ in visible light region [9]. Yu et al synthesized Fe-ion doped $\mathrm{TiO}_{2}$ thin films via liquid phase deposition and studied the effects of calcination temperatures on photocatalytic activities [18]. They also adopted the sol-gel process

\footnotetext{
* Corresponding author. Tel.: +886223651428.

E-mail address: chlu@ntu.edu.tw (C.-H. Lu).
}

to prepare $\mathrm{Fe}$-ion doped $\mathrm{TiO}_{2}$ films and investigated the influence of Fe-ion doping on the hydrophilicity of $\mathrm{TiO}_{2}$ films [19]. Sonawane et al have studied the effects of Fe-ion concentration on the photocatalytic properties of $\mathrm{TiO}_{2}$ thin films [21]. In the previous studies, high-temperature annealing is usually required for obtaining crystallized $\mathrm{TiO}_{2}$ films. Annealing at high temperatures will cause the species in the substrates to diffuse into the $\mathrm{TiO}_{2}$ film. Therefore, the photocatalytic activities of $\mathrm{TiO}_{2}$ will be reduced due to the inter-diffusion and interaction between the film and substrate [22].

To reduce the crystallization temperature of $\mathrm{Fe}^{3+}$-doped $\mathrm{TiO}_{2}$ thin films, a high-pressure crystallization (HPC) process was employed to anneal the thin films at low temperatures. The HPC process can be carried out at a relatively low temperature to prevent diffusion between the film and the substrate [23-25]. In this study, $\mathrm{Fe}^{3+}$-doped $\mathrm{TiO}_{2}$ thin films were synthesized via the HPC processes and the conventional annealing process. The phases in the thin films prepared via these two processes were investigated. The annealing temperature effects on the surface morphology of the formed films were studied. The photocatalytic activities of the films obtained via two different processes were also analyzed under visible light.

\section{Experimental}

Iron-ion doped titanium dioxide films were prepared via a metalorganic deposition method. Titanium tetraisopropoxide and ferric nitrate were employed as the metalorganic solution source, and 2-methoxylethanol was used as the solvent. This solution had a 
nominal 3\% iron-ion concentration with respect to the titania molar percentage. The metalorganic solution was coated onto cleaned glass substrates via a spin-coating process. The coated precursor films were dried on a hot plate at $150^{\circ} \mathrm{C}$ for $10 \mathrm{~min}$ to remove the organic solvent.

The as-pyrolyzed films were annealed via two different crystallization processes: the atmospheric-pressure annealing process and the high-pressure crystallization (HPC) process. The first process heated the films at $300^{\circ} \mathrm{C}$ for $30 \mathrm{~min}$ to evaporate the residual organics, and then annealed these films in a furnace under atmospheric pressure ( $14.7 \mathrm{psi}$ ) from 300 to $600^{\circ} \mathrm{C}$ for $2 \mathrm{~h}$. The second process annealed the films via a high-pressure (14.7-228.6 psi) crystallization process at $100-200^{\circ} \mathrm{C}$ for $2 \mathrm{~h}$. The as-pyrolyzed films were annealed in a sealed stainless-steel bomb to achieve crystallization. The bottom of the bomb was filled with distilled water to produce a high vapor-pressure environment at elevated temperatures. The films were positioned above the water surface to avoid direct contact with water during processing. The pressure in the bomb was modulated by the saturated vapor pressure.

The formed phases were examined via X-ray diffraction (XRD) using $\mathrm{Cu} K \alpha$ radiation. The crystallization of the prepared films at the different depths was investigated via grazing incident X-ray diffraction (GIXD). The diffuse reflectance spectra were measured using a UV-vis spectrophotometer. The morphology and the particle size of the prepared samples were investigated via scanning electron microscope (SEM). Methylene blue solution was used to determine the photocatalytic activities of the prepared films. A $30 \mathrm{~W}$ FL lamp was employed as a light source and a $400 \mathrm{~nm}$ glass filter was utilized to cut off light with wavelength shorter than $400 \mathrm{~nm}$. The quantitative measurement of the methylene blue concentration was performed by measuring the absorbance peak of methylene blue at $664 \mathrm{~nm}$ using a UV-vis spectrophotometer. The decolorization degree was calculated by calibration between the measured absorbance and methylene blue solution concentration. The decolorization value can be obtained using the following equation:

$D=1-\frac{C}{C_{0}}$

where $D$ represents the decolorization degree, $C_{0}$ is the beginning methylene blue concentration, and $C$ is the final methylene blue concentration.

\section{Results and discussion}

$\mathrm{Fe}^{3+}$-doped $\mathrm{TiO}_{2}$ thin films were prepared via the atmosphericannealing and high-pressure crystallization processes. The XRD patterns of the prepared films are illustrated in Fig. 1. As seen in Fig. 1(a), when the film was annealed at $300^{\circ} \mathrm{C}$ under atmospheric pressure, only amorphous film was obtained. When the annealing temperature increased to $325^{\circ} \mathrm{C}, \mathrm{Fe}^{3+}$-doped $\mathrm{TiO}_{2}$ thin film with an anatase phase was formed. After annealing at 400 and $600^{\circ} \mathrm{C}$, the crystallinity of the thin films was further enhanced. During the high-pressure crystallization (HPC) process, when the as-pyrolyzed film was annealed at $100^{\circ} \mathrm{C}$ under $14.7 \mathrm{psi}$ for $2 \mathrm{~h}$, the formed film still remained amorphous. However, after annealing at $125^{\circ} \mathrm{C}$ under $34.1 \mathrm{psi}$, the amorphous film was converted into crystallized films with an anatase phase, as seen in Fig. 1(b). In comparison with the conventional annealing process under atmospheric pressure, the HPC process significantly reduced the crystallization temperature from 325 to $125^{\circ} \mathrm{C}$. When the as-pyrolyzed films were annealed at 150,175 , and $200^{\circ} \mathrm{C}$ under $70,131.2$, and 228.6 psi, respectively, the crystallinity of thin films was gradually increased. The HPC process is considered to lead to a reduction in the critical free energy required for the formation of stable nuclei, thereby facilitating the nucleation process at low temperatures $[26,27]$.

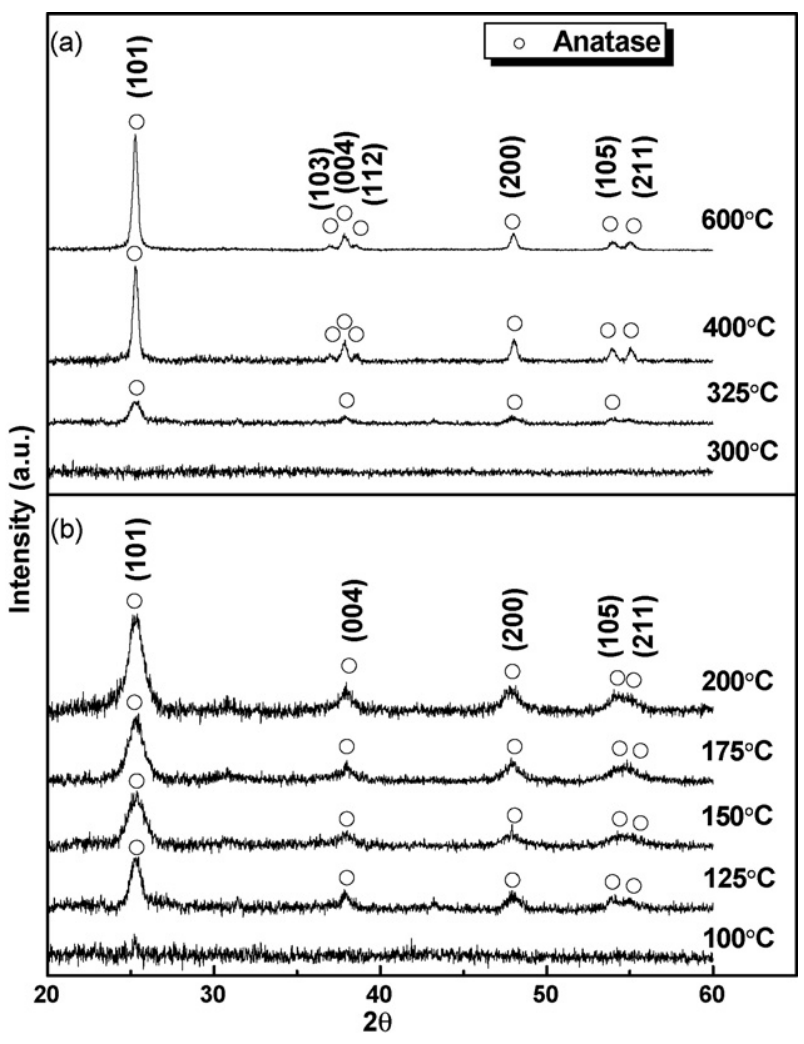

Fig. 1. X-ray diffraction patterns for $\mathrm{Fe}^{3+}$-doped $\mathrm{TiO}_{2}$ films prepared via (a) the conventional atmospheric-pressure annealing process and (b) the high-pressure crystallization process.

The surface morphology of $\mathrm{Fe}^{3+}$-doped $\mathrm{TiO}_{2}$ thin films annealed via the atmospheric pressure and high-pressure processes were investigated. After annealing at $600^{\circ} \mathrm{C}$ under atmospheric pressure, the size of particles in the film was around $60 \mathrm{~nm}$ as seen in Fig. 2(a). The high-temperature heating promotes the coarsening of the particles and form nonuniform surface. As seen in Fig. 2(b), the film annealed at $150^{\circ} \mathrm{C}$ under $70 \mathrm{psi}$ in the HPC process revealed a uniform surface morphology and a reduced particle size of around $30 \mathrm{~nm}$. When the film was annealed at $200^{\circ} \mathrm{C}$ under $228.6 \mathrm{psi}$, the average particle size of the thin film was slightly enlarged to $50 \mathrm{~nm}$ observed in Fig. 2(c). In comparison with the thin films prepared under atmospheric pressure, the thin films annealed under highpressure process exhibited a more uniform and denser morphology with reduced grain size.

The photocatalytic activities of the prepared films under visible light $(>400 \mathrm{~nm}$ ) were evaluated based on the decomposition behavior of methylene blue solution. Fig. 3 illustrates the photocatalytic activities of the films prepared via the HPC process as a function of annealing temperatures. After $19 \mathrm{~h}$-illumination under visible light, the decolorization degree of the methylene blue solutions were $74.4,88.4,91.9$, and $94.4 \%$ for the films annealed at 125 , 150,175 , and $200^{\circ} \mathrm{C}$, respectively. It was found that the decorlorization degree increased markedly with an increase in the annealing temperatures under the HPC process, due to the enhancement of crystallinity of $\mathrm{TiO}_{2}$ anatase phase. Yu et al also reported that the photocatalytic activity of $\mathrm{TiO}_{2}$ significantly depends on its crystallinity, microstructure, surface area and crystal structure [28]. The UV-vis spectrum of methylene blue degraded by the thin film annealed via the conventional annealing process is also shown in Fig. 3. The decolorization degree of methylene blue solution was $67.9 \%$ for the film annealed at $600{ }^{\circ} \mathrm{C}$. The UV-vis absorption spectrum of the samples annealed at $200^{\circ} \mathrm{C}$ is illustrated in Fig. 4, which 

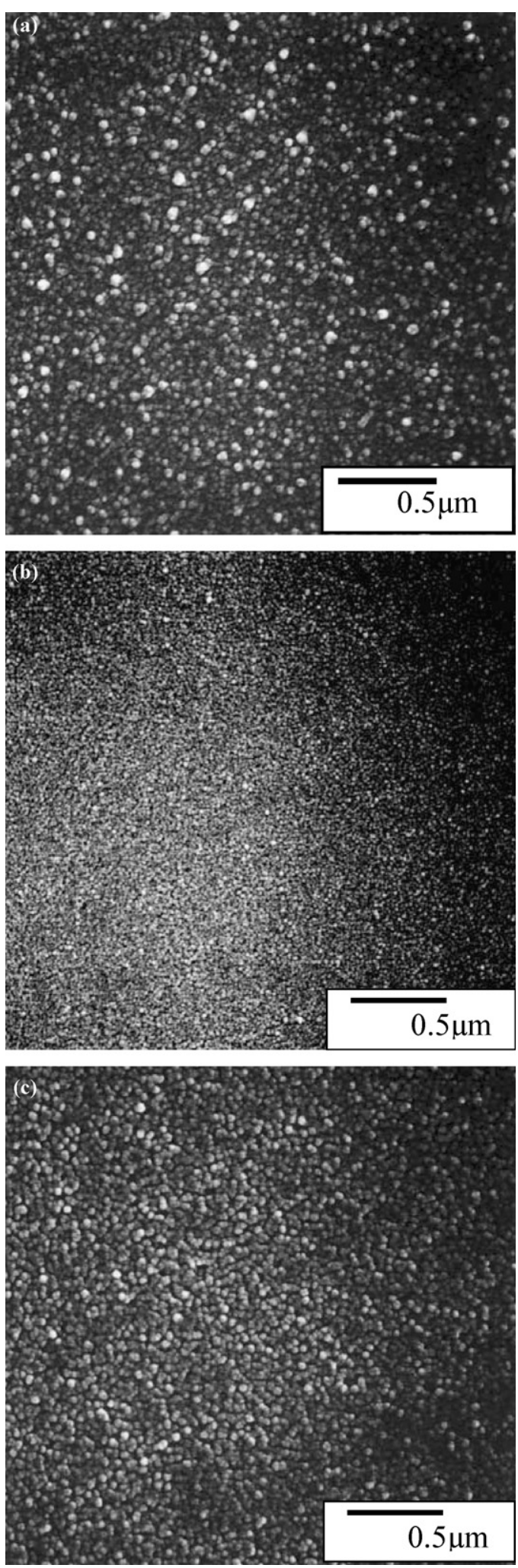

Fig. 2. Scanning electron micrographs of $\mathrm{Fe}^{3+}$-doped $\mathrm{TiO}_{2}$ thin films annealed at (a) $600{ }^{\circ} \mathrm{C}$ under atmospheric pressure, (b) $150{ }^{\circ} \mathrm{C}$ under $64 \mathrm{psi}$ and (c) $200^{\circ} \mathrm{C}$ under 228.6 psi.

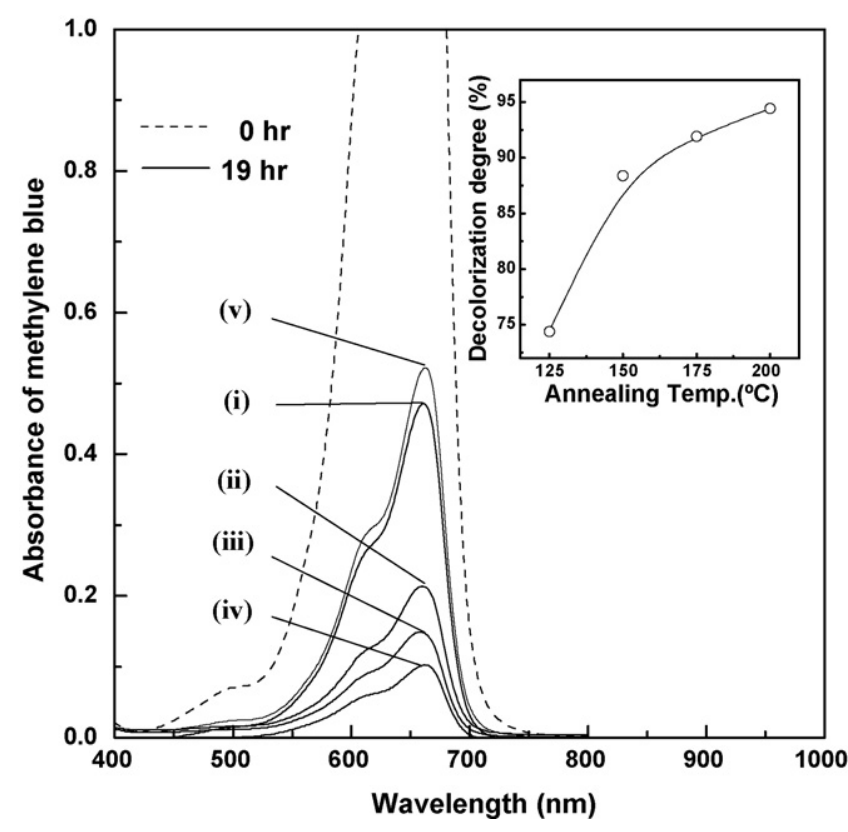

Fig. 3. UV-vis spectra of methylene blue degraded by $\mathrm{Fe}^{3+}$-ion doped $\mathrm{TiO}_{2}$ thin films annealed at (i) $125^{\circ} \mathrm{C}$, (ii) $150^{\circ} \mathrm{C}$, (iii) $175^{\circ} \mathrm{C}$, (iv) $200^{\circ} \mathrm{C}$ via the HPC process and (v) $600^{\circ} \mathrm{C}$ under atmospheric pressure.

confirms visible light absorption in the Fe-ion doped samples. The above results revealed that iron-ion doped titania thin films prepared via the HPC process showed greater photocatalytic activities than those obtained from the conventional annealing process. It was concluded that the smaller sized particles and denser structures formed in the films were beneficial to the photocatalytic activities of these films. The quantum yields of the prepared films were calculated according to the method proposed in the literature [29]. The obtained values for the films heated at 125, 150, 175 and $200^{\circ} \mathrm{C}$ were $0.5,0.8,0.9$ and $1.0 \%$, respectively. The obtained values are comparable to the data reported in literature for the visible-light sensitized $\mathrm{TiO}_{2}$ films [30,31]. The quantum yield of the films was

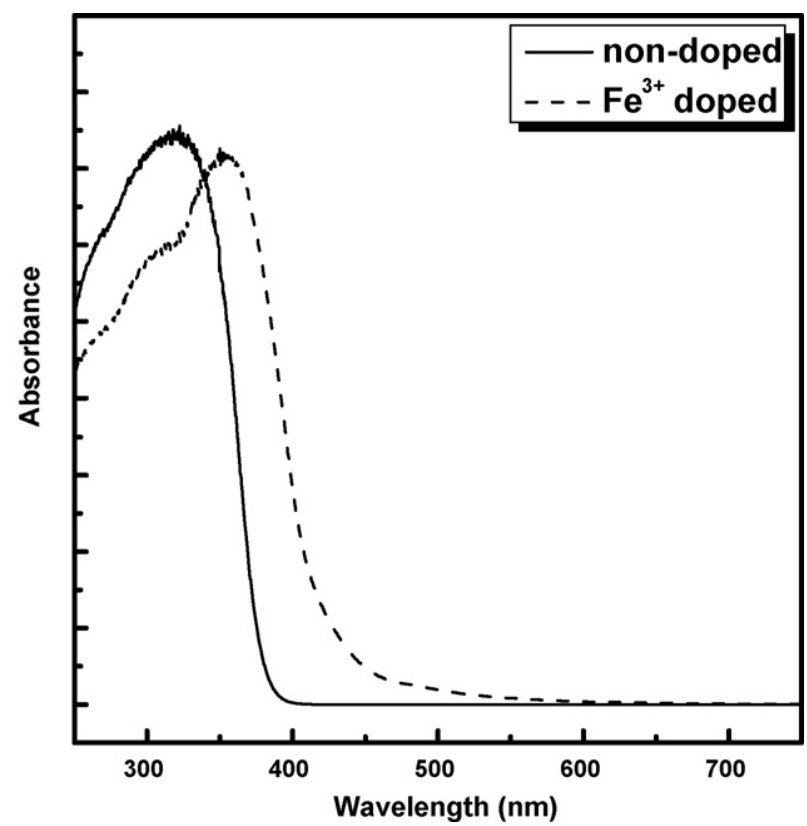

Fig. 4. UV-vis absorption spectra of non-doped and $\mathrm{Fe}^{3+}$-ion doped $\mathrm{TiO}_{2}$ annealed at $200^{\circ} \mathrm{C}$. 


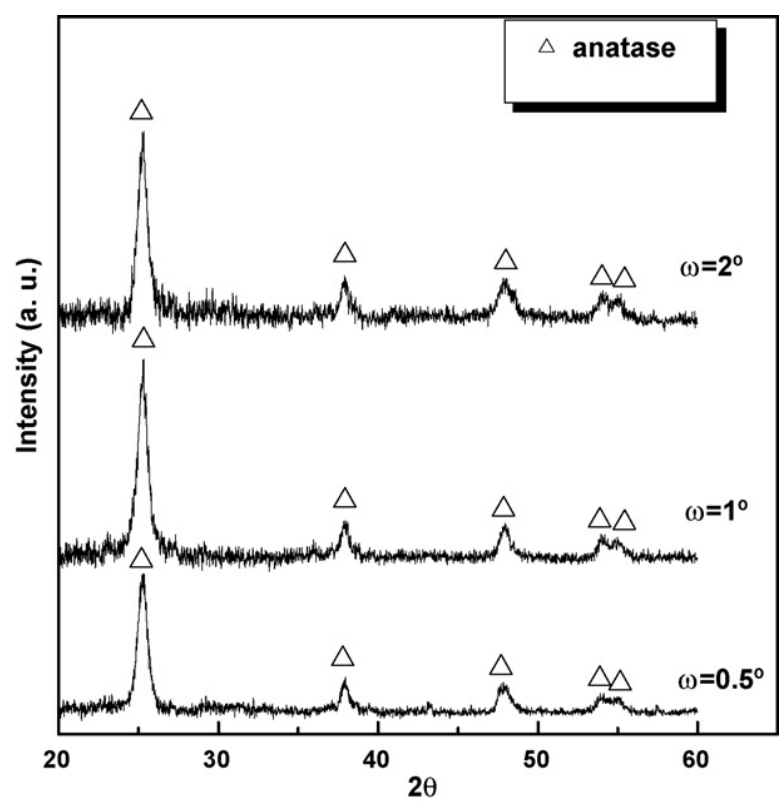

Fig. 5. Grazing incident X-ray diffraction patterns of $\mathrm{Fe}^{3+}$-doped $\mathrm{TiO}_{2}$ thin film annealed at $200^{\circ} \mathrm{C}$ under $228.6 \mathrm{psi}$.

found to increase with raising annealing temperatures as a result of enhanced crystallization.

Grazing incident X-ray diffraction (GIXD) was employed for investigating the crystallization state within the prepared films. The GIXD patterns for the $200^{\circ} \mathrm{C}$-annealed film prepared via the HPC process are illustrated in Fig. 5. The X-ray penetration depth was calculated according to the following equation [32]:

$D(\omega)=\frac{\sin (\omega)}{\mu}$

where $\omega$ is incident angle of the X-ray beam and $\mu$ is the linear absorption coefficient. The penetration depths were calculated at about $0.141,0.282$, and $0.564 \mu \mathrm{m}$ for incident angles $0.5^{\circ}, 1^{\circ}$, and $2^{\circ}$, respectively. The penetration depths of the X-ray into the thin films became deeper with increasing X-ray beam incident angles. From Fig. 5, similar intensities in the $\mathrm{Fe}^{3+}$-doped $\mathrm{TiO}_{2}$ thin film diffraction peaks can be observed. This implies that the crystallinity within the films is almost the same. It reveals that the crystallization process took place within whole films.

The above results indicate that iron-ion doped titania thin films annealed via the HPC process revealed better photocatalytic properties under visible light illumination than the atmosphericannealed films. The prepared films exhibited more uniform structure and had a smaller particle size than films annealed via the conventional annealing process. The HPC process is considered a potential method for preparing visible-light driven $\mathrm{TiO}_{2}$ films at low temperatures.

\section{Conclusions}

Iron-ion doped titania thin films were prepared via atmospheric-pressure annealing and high-pressure crystallization (HPC) processes in this study. The HPC process successfully reduced the crystallization temperature of $\mathrm{TiO}_{2}$ as low as $125^{\circ} \mathrm{C}$. In comparison to thin films prepared under atmospheric pressure, the thin films prepared via the HPC process exhibited more uniform microstructure with a smaller grain size. The films prepared via both processes were found to have photocatalytic characteristics under visible light. However, the films prepared via the HPC process exhibited better photocatalytic activities than the films prepared via the atmospheric-pressure annealing process. When the heating temperature was increased in the HPC process, the photocatalytic properties of titania thin films were further improved due to the increase in crystallinity. The HPC process was demonstrated an approach with good potential for preparing visible-light driven titania films at relatively low temperatures.

\section{References}

[1] N. Negishi, T. Iyoda, K. Hashimoto, A. Fujishima, Chem. Lett. 9 (1995) 841

[2] M.R. Hoffmann, S.T. Martin, W. Choi, D.W. Bahnemann, Chem. Rev. 95 (1995) 69.

[3] G. Wang, Mol. Catal. A: Chem. 274 (2007) 185.

[4] D.F. Oills, E. Pelizzetti, N. Serpone, Environ. Sci. Technol. 25 (1991) 1522.

[5] Y. Zhu, L. Zhang, C. Gao, L. Cao, J. Mater. Sci. 35 (2000) 4049.

[6] L.F. Cueto, G.A. Hirata, E.M. Sanchez, J. Sol-Gel Sci. Technol. 37 (2006) 105.

[7] M. Kang, J.H. Lee, S.H. Lee, C.H. Chung, K.J. Yoon, K. Ogino, S. Miyata, S.J. Choung, J. Mol. Catal. A-Chem. 193 (2003) 173.

[8] P.K. Song, Y. Irie, Y. Shigesato, Thin Solid Films 496 (2006) 121.

[9] M. Zhou, J. Yu, B. Cheng, J. Hazard. Mater. 137 (2006) 1838.

[10] X. Hong, Z. Wang, W. Cai, F. Lu, J. Zhang, Y. Yang, N. Ma, Y. Liu, Chem. Mater. 17 (2005) 1548.

[11] M. Zhou, J. Yu, B. Cheng, H. Yu, Mater. Chem. Phys. 93 (2005) 159.

[12] M.I. Litter, Appl. Catal. B: Environ. 23 (1999) 89.

[13] J.M. Herrmann, H. Tahiri, C. Guillar, P. Pichat, Catal. Today 54 (1999) 131.

[14] B. Xin, Z. Ren, P. Wang, J. Liu, L. Jing, H. Fu, Appl. Surf. Sci. 253 (2007) 4390.

[15] Y. Zhu, L. Zhang, L. Wang, Y. Fu, L. Cao, J. Mater. Chem. 11 (2001) 1864.

[16] M. Radecka, K. Zakrzewska, M. Wierzbicka, A. Gorzkowska, S. Komornicki, Solid State Ionics 157 (2003) 379.

[17] J. Osterwalder, T. Droubay, T. Kaspar, J. Williams, C.M. Wang, S.A. Chambers, Thin Solid Films 484 (2005) 289.

[18] J. Yu, H. Yu, C.H. Ao, S.C. Lee, J.C. Yu, W. Ho, Thin Solid Films 496 (2006) 273.

[19] J. Yu, M. Zhou, H. Yu, Q. Zhang, Y. Yu, Mater. Chem. Phys. 95 (2006) 193.

[20] S.H. Woo, W.W. Kim, S.J. Kim, C.K. Rhee, Mater. Sci. Eng. A 449-451 (2007) 1151

[21] R.S. Sonawane, B.B. Kale, M.K. Dongare, Mater. Chem. Phys. 85 (2004) 52.

[22] J. Yu, X. Zhao, Mater. Res. Bull. 35 (2000) 1293.

[23] C.H. Lu, US Patent No. 6,143,366 (2000).

[24] C.H. Lu, Y.C. Chen, Y.C. Sun, J. Mater. Chem. 12 (2002) 1628

[25] C.H. Lu, W.J. Hwang, Y.C. Sun, Jpn. J. Appl. Phys. 41 (2002) 6674

[26] S.C. Liao, W.E. Mayo, K.D. Pae, Acta Mater. 45 (1997) 4027.

[27] K.W. Seo, J.K. Oh, J. Ceram. Soc. Jpn. 108 (2000) 691.

[28] J. Yu, Y. Su, B. Cheng, Adv. Funct. Mater. 17 (2007) 1984.

[29] P. Kluson, M. Drobek, T. Strasak, J. Krysa, M. Karaskova, J. Rakusan, J. Mol. Catal. Chem. 272 (2007) 213.

[30] S. Sato, R. Nakamura, S. Abe, Appl. Catal. A: Gen. 284 (2005) 131

[31] D. Li, H. Haneda, N. Labhsetwar, S. Hishita, N. Ohashi, Chem. Phys. Lett. 401 (2005) 579.

[32] C.H. Lu, Y.C. Wen, J. Appl. Phys. 86 (1999) 6335. 